\title{
ARTESANATO NOS ESTUDOS ORGANIZACIONAIS: A LITERATURA BRASILEIRA DE 2006 A 2015'
}

CRAFTS IN ORGANIZATIONAL STUDIES: THE BRAZILIAN LITERATURE FROM 2006 TO 2015

\author{
Recebido em 22.12.2016. Aprovado em 21.03.2017 \\ Avaliado pelo sistema double blind review \\ DOI: http://dx.doi.org/10.12712/rpca.v11i2.880
}

\section{Arilton Marques Faria}

arilton98@gmail.com

Universidade Federal do Espírito Santo (UFES), Vitória/ES, BRASIL

\section{Alfredo Rodrigues Leite da Silva}

alfredoufes@gmail.com

Universidade Federal do Espírito Santo (UFES), Vitória/ES, BRASIL

\begin{abstract}
Resumo
O objetivo deste estudo foi compreender as maneiras pelas quais pesquisadores do campo dos estudos organizacionais brasileiros utilizaram o artesanato em suas investigações. A discussão se baseou em uma pesquisa bibliométrica sobre o tema nos periódicos nacionais classificados acima do nível B5 na avaliação de 2014 da CAPES. Foi identificada uma amostra de 54 artigos, distribuídos entre 30 periódicos. Como resultado, duas pesquisadoras, da UNIFOR e da UFRGS, e essas instituições as quais estão vinculadas, foram as mais recorrentes na amostra. Também se destacaram dois periódicos, RIGS e O\&S, e o tema pesca artesanal. Em 2012, ocorreu a publicação do maior número de artigos. Foi possível identificar o predomínio de artigos empíricos, estudos qualitativos, estratégia metodológica do estudo de caso, entrevista como técnica de coleta e análise de conteúdo como técnica de análise dos dados empíricos. Ao final, os resultados permitiram reflexões sobre o tema e uma agenda de pesquisa.
\end{abstract}

Palavras-chave: Artesanato. Estudos Organizacionais. Bibliometria.

\begin{abstract}
The goal of this study was to comprehend the ways in which researchers of the field of Brazilian organizational studies have used craft in your investigations. The discussion was based on a bibliometric research about the theme in national journals classified above B5 level in CAPES evaluation of 2014. It was identified a sample of 54 papers, distributed between 30 journals. As result, two researchers, from UNIFOR and UFRGS, and these institutions in which they are linked, were the most recurrent on the sample. In addition, it was stood out two journals, RIGS and O\&S, and the artisanal fishing theme. In 2012, it was happen the publication of the major number of papers. It was possible to identify predominance of empirical papers, qualitative studies, case study methodological strategy, interview as data gathering technique and content analysis as analysis technique of empirical data. At the end, results allowed reflections about the theme and a research agenda.
\end{abstract}

Keywords: Crafts. Organizational Studies. Bibliometrics.

\footnotetext{
${ }^{1}$ Os autores agradecem à FAPES e ao CNPQ pelo apoio financeiro.
} 


\section{Introdução}

Figura 1. Artesanato de conchas em Piúma Espírito Santo

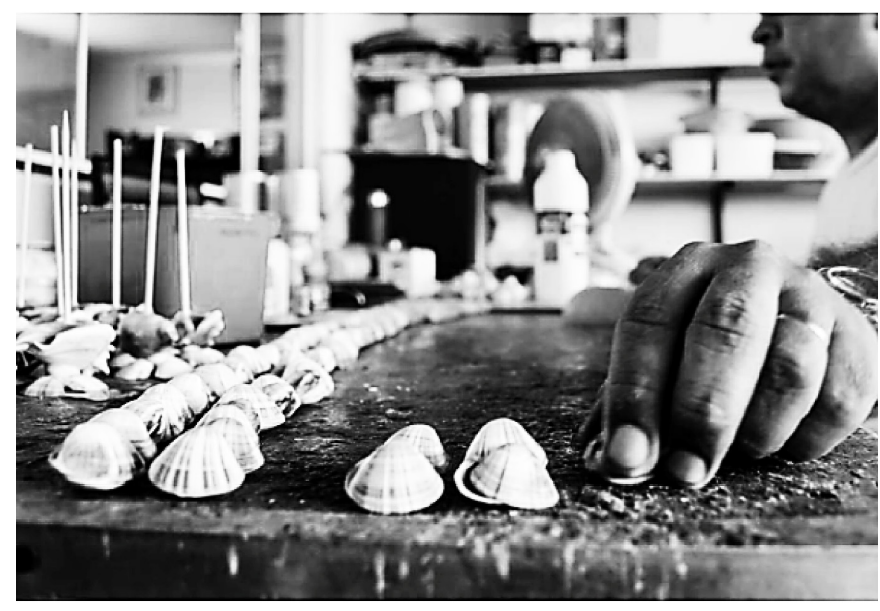

Fonte: Bodart (2016).

A Figura 1 foi retirada de um ensaio fotoetnográfico sobre o artesanato de conchas do município de Piúma, no estado do Espírito Santo. Nos últimos anos, essa atividade tem sustentado diversas famílias nesse município, além de manter uma das tradições locais (BODART, 2016). Dessa maneira, Piúma tem sido um exemplo revelador de como o artesanato ainda sobrevive em muitas localidades brasileiras. Segundo estimativas governamentais da década passada, aproximadamente 8,5 milhões de brasileiros trabalhavam com essa atividade (IBGE, 2010).

Esse contexto tem proporcionado um profícuo caminho para estudiosos de diversas áreas interessados em desvendar o artesanato. Atividade que tem sido confundida com a história da humanidade, o artesanato já passou por períodos de significativa valorização em larga parcela da sociedade e também por períodos de desprezo, ocorrendo esses últimos na maior parte do tempo. A "fase de ouro" do artesanato na sociedade grega antiga, por exemplo, deu-se no período arcaico ao qual contava, inclusive, com um deus dos artesãos, Hefesto (SENNET, 2009). No período clássico grego, contudo, o artesanato passou a ser desprezado, pois, nessa época, o trabalho intelectual importava mais do que o trabalho manual (SENNET, 2009).

Foi principalmente na era medieval europeia que o artesanato ganhou novo impulso com o aparecimento do mestre artesão e das guildas (GRANDE et al., 2012). Nesse período medievo, a Igreja contava com significativo poderio com o qual ela legitimava o artesanato como atividade digna e capaz de ocupar as mãos das pessoas, já que o tempo livre atraía tentação (SENNET, 2009). Com o renascimento cultural europeu, o artesanato se separou da arte e foi negado pela elite monárquica, pois essa encarava a atividade como algo vulgar das baixas camadas da sociedade. $\mathrm{Na}$ fase da industrialização, o artesanato continuou em declínio, pois era visto como atividade ineficiente se comparada com as máquinas industriais (GRANDE et al., 2012). E na contemporaneidade, o artesanato tem sobrevivido em movimentações que incluem o movimento neoliberal de empresarização da atividade (MARQUESAN, FIGUEIREDO, 2014).

Já nos estudos organizacionais contemporâneos, o artesanato tem buscado legitimidade enquanto uma temática relevante de estudo, por oferecer contribuições sobre as maneiras de estudar organizações a partir de óticas comumente não abordadas no campo. Figueiredo e Marquesan (2014) argumentam que o artesanato é algo relevante, capaz de merecer atenção dos pesquisadores dessa área de estudos, haja vista a possibilidade que esse tema de estudo tem para propiciar maneiras distintas de articular estudos organizacionais. Ao se considerar $\mathrm{o}$ artesanato enquanto materialidade e prática, notase que ele contém características singulares que o transformam em argumento relevante para se refletir sobre a articulação entre pessoas, ambiente e artefatos nas organizações (FIGUEIREDO, 2014).

Dentrodocampodeestudosorganizacionaiséevidente, portanto, que o artesanato tem ganhado atenção de alguns autores. Entretanto, não se encontrou na literatura trabalhos que buscassem uma sistematização sobre os próprios estudos em torno dessa temática. Assim, o problema que guiou esta investigação foi o seguinte: como o artesanato foi utilizado pela literatura brasileira dos estudos organizacionais nos últimos dez anos? Portanto, o objetivo do estudo foi compreender as maneiras pelas quais pesquisadores do campo dos estudos organizacionais brasileiros utilizaram o artesanato em suas investigações. Para alcançar esse objetivo, a estratégia metodológica usada foi a pesquisa bibliométrica, com uma amostra final de 54 artigos, que foram analisados quantitativamente, por meio de estatística descritiva.

A estrutura deste artigo foi definida da seguinte maneira: na sequência desta parte introdutória, encontra-se uma discussão a respeito da articulação entre os estudos sobre artesanato e os estudos 
organizacionais; então, apresenta-se o percurso metodológico, seguido dos resultados, para se encerrar com as considerações finais.

\section{Do artesanato aos estudos organizacionais}

Desde os primeiros agrupamentos humanos pelo mundo, principalmente com o movimento de transição das formas nômades de vida para o seminomadismo e o sedentarismo, os seres humanos têm lidado com o artesanato, fazendo com que a história dessa atividade se entrelace com a história da humanidade. A ocupação do atual território brasileiro é um exemplo revelador de como tal dinâmica já se manifestava há séculos. Muito antes da chegada dos europeus, notava-se o desenvolvimento de diversas tradições arqueológicas com diferentes manifestações culturais no atual território do Brasil, tais como as tradições Humaitá (região sul), Umbu (região sul), Itararé (região sul), Taquara (região sul), Aratu (região sudeste), Guarita (região norte), além das cerâmicas feitas pelos povos tupis-guaranis conhecidas como cultura santarém e cultura marajoara (ambas na região norte) (PROUS, 1992).

Outro caso de manifestações culturais em torno do artesanato é o da antiguidade grega, contexto em que o artesanato teve sua fase de prestígio, que se deu no período arcaico (SENNET, 2009) com a formação da pólis aristocrática. Nessa fase, as explicações acerca do mundo estavam exclusivamente centradas na consciência mítica. É na mitologia grega que se encontra uma das primeiras celebrações ao artesanato: o hino homérico ao deus dos artesãos, Hefesto (SENNET, 2009). O artesão da fase arcaica na antiguidade grega ocupava uma posição social parecida com a posição da classe média estadunidense do contexto contemporâneo (SENNET, 2009). Mas com a chegada do período clássico da civilização grega - período marcado pelo pensamento filosófico clássico, o artesanato passou a ser desprezado (SENNET, 2009).

O artesanato só viria a receber tratamento diferenciado com o surgimento da Europa na era medieval. Nesse contexto, a influência do artesão na sociedade seria significativa caso ele fosse um cristão, pois o cristianismo, desde suas origens, havia abraçado o trabalho artesanal como um trabalho digno e abençoado (SENNET, 2009). O ócio era visto como tentação e indolência pela Igreja, fazendo-se necessária a ocupação do tempo com algum trabalho manual (SENNET, 2009). As práticas religiosas da idade média abarcavam o artesanato de maneira profunda, tanto que foi no contexto dos mosteiros europeus medievais, especificamente no século XI, que apareceu a figura do mestre artesão (GRANDE et al., 2012).

Mais tarde, especialmente no século XIII, as chamadas corporações de ofício (guildas ou oficinas artesanais) já estavam consolidadas (GRANDE et al., 2012). Nessas oficinas, os artesãos comiam, dormiam e criavam seus filhos, sendo que, tais locais de trabalho e moradia eram relativamente pequenos, comportando não mais do que algumas dezenas de pessoas (SENNET, 2009). A hierarquia na oficina medieval era constituída por três níveis: na base estava o aprendiz, no meio se encontrava o jornaleiro e no topo estava o mestre artesão (SENNET, 2009). A despeito da existência de alguns procedimentos formalizados no dia a dia (como o treinamento para o teste de progresso chamado de chef d'oeuvre), as relações entre as pessoas que trabalhavam na oficina se davam de maneira familiar (GRANDE et al., 2012). E mesmo com a hierarquização, o artesão se valia da unidade da concepção e execução do trabalho (GRANDE et al., 2012).

Contudo, essa unidade de concepção e execução não permaneceu viva na era moderna com a chegada da industrialização, que teve sua origem na Inglaterra e depois se espalhou pelo mundo. No contexto estadunidense, por exemplo, o taylorismo foi um movimento que acabou com a unidade de concepção e execução na produção de automóveis (GRANDE et al., 2012). Em termos mais amplos, significativa parcela dos produtos ganhou tratamento produtivo em larga escala com o uso de máquinas industriais (MAZZA; IPIRANGA; FREITAS, 2007). Tais máquinas representaram um enorme dilema para o artesão moderno, não se sabendo se elas seriam amistosas ou inimigas que chegariam para substituir o trabalho artesanal, porém, esse último caminho foi o que mais se verificou em várias situações da época (SENNET, 2009).

$\mathrm{Na}$ mesma época da industrialização, desenvolviamse os ideais iluministas os quais defendiam, entre outros pontos, a valorização do artesanato, buscando a igualdade entre as atividades manuais e as atividades intelectuais (SENNET, 2009). Isso representava uma provocação em relação à elite do absolutismo que se perpetuava desde o renascimento, em uma 
época em que o trabalho artesanal era considerado vulgar (SENNET, 2009). Ao mesmo tempo, aqueles ideais iluministas serviram de base para a ascensão e posterior legitimação da hegemonia burguesa, que contribuiria mais tarde com a desvalorização do artesanato perante o capital globalizado com a chegada da chamada sociedade pós-industrial, após a Segunda Guerra Mundial, quando houve um crescimento exponencial de bens imateriais, especialmente os serviços (MAZZA; IPIRANGA; FREITAS, 2007).

Dentro dessa trajetória o artesanato se inseriu, nesses últimos tempos, em uma lógica de contradições que envolve, ao mesmo tempo, a tradição e a inovação, a máquina e a mão, o rápido e o lento, a massificação e a excelência (GRANDE, et al., 2012). Acima de tudo, $\mathrm{o}$ artesanato contemporâneo tem sido marcado pelo movimento gerencialista com a intenção de enquadrar a atividade artesanal à lógica capitalista, o que tem acarretado, em muitos casos, perda de autenticidade da atividade (MARQUESAN; FIGUEIREDO, 2014).

Ademais, essa empresarização do artesanato alimenta relações de poder distribuídas em nível macrossocial envolvendo várias instituições, como governos e empresas, mas, principalmente, tal movimento participa e contribui com o fluir de relações de poder disseminadas no cotidiano do artesanato. Um cotidiano do qual participam sujeitos ordinários em uma dinâmica reconhecida pela luta entre tais sujeitos com suas práticas diárias baseadas em estratégias e táticas (CERTEAU, 1998). Um cotidiano que é dado diariamente àqueles sujeitos anônimos e que os oprime, pois existem opressões cotidianas, mas, tais opressões não lidam com sujeitos passivos, tendo em vista que aparecem momentos aos quais os sujeitos ordinários podem articular minúsculas transgressões como formas de sobrevivência (CERTEAU; GIARD; MAYOL, 2009).

Essas transgressões de praticantes ordinários podem ser vistas como estratégias subversivas em torno do artesanato como atividade inserida no campo artístico (BOURDIEU, 2005). O campo artístico se trata de um campo de forças e de batalhas. Campo de forças porque ele é "uma rede de determinações objetivas que pesam sobre todos os que agem no seu interior" (WACQUANT, 2005, p. 117). Também se trata de um campo de batalhas, pois ele é marcado por uma dinâmica entre estratégias conservadoras por agentes de posições privilegiadas e estratégias subversivas por agentes marginalizados (BOURDIEU, 2005). Esse campo vira um jogo no qual os agentes são cúmplices de segredos que levam tais agentes a transformarem suas posições em determinados momentos, o que vai depender, entre outros fatores, das qualidades dos capitais artísticos usados nas disputas (BOURDIEU, 2005).

Essa lógica de diferentes posições no campo artístico tem papel central na diferenciação entre arte $e$ artesanato. Embora a arte e o artesanato se valham de materiais e técnicas muito próximas e até iguais em alguns casos, tradicionalmente o artesanato tem sido tratado de forma inferior com relação à arte, principalmente quando se trata de "belas artes" (FIGUEIREDO; MARQUESAN, 2014). A arte tem sido tratada como função estética eminentemente instável correspondendo a dado momento histórico, enquanto que o artesanato tem sido tratado como função prática que se mantém estável durante um tempo (FIGUEIREDO; MARQUESAN, 2014). Além disso, a arte se apresenta à experiência da percepção como um profundo exercício de alteridade potencialmente contemplativo e o artesanato se mostra à percepção como uma articulação processual que circunda a experiência material (FIGUEIREDO; MARQUESAN, 2014). A arte pretende exprimir emoção, enquanto o artesanato tem propósito mais prático (OLIVEIRA; CAVEDON; FIGUEIREDO, 2012). A arte conta com um agente dominante, enquanto que o artesanato conta com um agente coletivo (SENNET, 2009).

Além dessa diferenciação entre partes internas do campo artístico, ele influencia e é influenciado por outros campos, entre os quais se encontra o campo acadêmico (BOURDIEU, 1988). Esse último é de enorme relevância na sua relação com o campo artístico, haja vista que muitos agentes do campo acadêmico se debruçam sobre o campo artístico, e no caso o artesanato, para discursar sobre ele. Nesse sentido, também é relevante notar como o artesanato tem sido tratado por diversas áreas de estudos. Considerável exemplo está nos estudos organizacionais, onde o artesanato se posiciona como um caminho de resistência frente aos enfoques dominantes (FIGUEIREDO; MARQUESAN, 2014). As teorias organizacionais acabaram esquecendo das formas organizativas artesanais (VERGARA; SILVA, 2007). A hegemonia tem se concentrado no gerencialismo da iniciativa privada com a visão funcionalista sobre a qual o artesanato acaba sendo menosprezado como algo "amador" (CARRIERI; PERDIGÃO; AGUIAR, 2014). Entretanto, o 
artesanato não é algo sem gestão, pois a gestão dessa forma de organizar existe; porém, diferencia-se da gestão instrumental das grandes empresas privadas, já que a gestão artesanal é do tipo ordinário (CARRIERI; PERDIGÃO; AGUIAR, 2014).

A gestão ordinária é aquela que se distancia dos padrões gerencialistas ao focar o dia a dia das pessoas comuns que lidam com negócios ordinários (CARRIERI; PERDIGÃO; AGUIAR, 2014). Ao se pesquisar a respeito desse tipo de gestão, privilegiase diversos pequenos negócios, entre os quais se encontra o artesanato. A relevância do artesanato para os estudos organizacionais está na possibilidade de desenvolvimento de formas alternativas de organizar (FIGUEIREDO; MARQUESAN, 2014). Também o artesanato pode propiciar a apreensão das várias formas de ser e viver em contextos organizacionais sob aspectos culturais, tais como a situação relacional entre atores sociais e os artefatos materiais (FIGUEIREDO, 2014). Portanto, parte-se da noção de que o artesanato, enquanto prática que tem sido encontrada desde tempos remotos e, até a contemporaneidade tem sido valorizada em curtos períodos e desvalorizada em outros, é uma fértil área de investigação nos estudos organizacionais. Porém, a dúvida que paira sobre o campo de estudos é sobre como essa temática tem sido tratada na área. Possíveis respostas se encontram nos resultados deste estudo, alcançados por meio do percurso metodológico apresentado a seguir.

\section{Procedimentos metodológicos}

Considerando o objetivo desta investigação, adotouse como método de pesquisa a bibliometria, haja vista seu significativo potencial de revelar as maneiras pelas quais uma comunidade acadêmica tem tratado determinada temática. Para Araújo (2006), a bibliometria é uma técnica estatística de medição da produção e disseminação do conhecimento científico. $\mathrm{O}$ autor explica que a técnica se desenvolveu no início do século XX pelo mundo e no Brasil expandiu-se a partir da década de 1970. Ainda segundo o autor, ao longo desses anos, os estudos bibliométricos foram reinventados e aplicados de variadas formas. Tal dinâmica também se apresentou nos estudos organizacionais com o aparecimento de algumas investigações com os propósitos bibliométricos. Alves e outros (2016), por exemplo, investigaram sobre a situação da economia solidária nos estudos organizacionais brasileiros. Tais autores fizeram uso de bases de periódicos para seleção da amostra. Já Costa e Andrade (2015) desenvolveram um estudo bibliométrico para investigar sobre comportamento de cidadania organizacional. Para isso, as autoras se basearam em três etapas: seleção de periódicos, seleção de artigos e análise.

$\mathrm{Na}$ mesma via desse último estudo, encontra-se esta investigação, que percorreu o caminho constituído das mesmas três etapas: seleção dos periódicos, seleção dos artigos e análise do material coletado. Para a seleção dos periódicos, adotou-se a lista de periódicos avaliados pela Coordenação de Aperfeiçoamento de Pessoal de Nível Superior (CAPES) e disponibilizados pela plataforma Sucupira. Escolheu-se a avaliação de 2014, da área de "Administração, Ciências Contábeis e Turismo" e das classificações A1, A2, B1, B2, B3 e B4. Isso resultou em uma lista com 949 periódicos (considerando como um só periódico aquele que apresentava a versão impressa e a versão online). A partir disso, excluiu-se os periódicos que não fossem nacionais ou que não apresentassem ligação com a área dos estudos organizacionais, sendo que, para isso, realizou-se uma busca no site de cada periódico a fim de obter tais informações. Com a aplicação desse filtro, 156 periódicos foram selecionados pelo fato de se enquadrarem nos quesitos anteriormente mencionados.

Desses 156 periódicos, realizou-se uma busca em cada revista a fim de se obter uma amostra de artigos. Por meio do sistema de busca de cada periódico foram selecionadas publicações do período de janeiro de 2006 a dezembro de 2015 com um dos seguintes termos no resumo: artesã; artesãs; artesão; artesãos; artesanato; artesanatos; artesanal; artesanais; artífice. Com isso, obteve-se um total de 80 artigos, que foram lidos integralmente com o intuito de apreender o tema e verificar se o artigo tinha relação com a área dos estudos organizacionais. Nos casos em que os artigos não apresentaram relação alguma com os estudos organizacionais, os mesmos foram excluídos. Dessa forma, a amostra final de artigos foi de 54, distribuídos entre 30 periódicos.

Os 54 artigos foram analisados a partir de duas dimensões. A primeira dimensão tratou das características gerais dos artigos: os autores, os periódicos, os anos de publicação, as instituições dos autores e os temas dos artigos. A segunda dimensão tratou de aspectos metodológicos, que inclui o tipo de artigo (ensaio teórico ou empírico), a natureza 
$\mathrm{da}$ pesquisa (quantitativa, qualitativa ou mista), o tratamento do tema artesanato ("lente de análise" ou "objeto de estudo"), estratégia metodológica, técnica de coleta e técnica de análise. Cada item foi discutido com o apoio de gráficos e métricas. Tais gráficos e métricas foram construídos com base no programa Microsoft Excel 2013®. A seguir, são apresentados os resultados da pesquisa.

\section{Resultados e discussão}

Na primeira dimensão foram analisadas as frequências referentes às características gerais dos artigos que abordaram o artesanato: os autores, os periódicos, os anos de publicação, as instituições dos autores e os temas dos artigos.

O Gráfico 1, a seguir, mostra que as pesquisadoras Marina Dantas Figueiredo (UNIFOR) e Neusa Rolita Cavedon (UFRGS) foram as autoras mais recorrentes, estando a primeira com 7 artigos e a segunda com 5 artigos, em um total de 54 artigos. Demais pesquisadores não alcançaram mais do que 3 artigos. Cabe esclarecer que as duas pesquisadoras em destaque mantêm laços acadêmicos, haja vista que a pesquisadora Marina D. Figueiredo foi orientada no doutorado justamente pela pesquisadora Neusa R. Cavedon, em uma tese envolvendo uma organização artesanal. Ambas as pesquisadoras se interessam pelo artesanato enquanto tema e por temáticas próximas ao artesanato, tais como cultura e organizações familiares.

Gráfico 1. Quantidade de artigos por pesquisadores

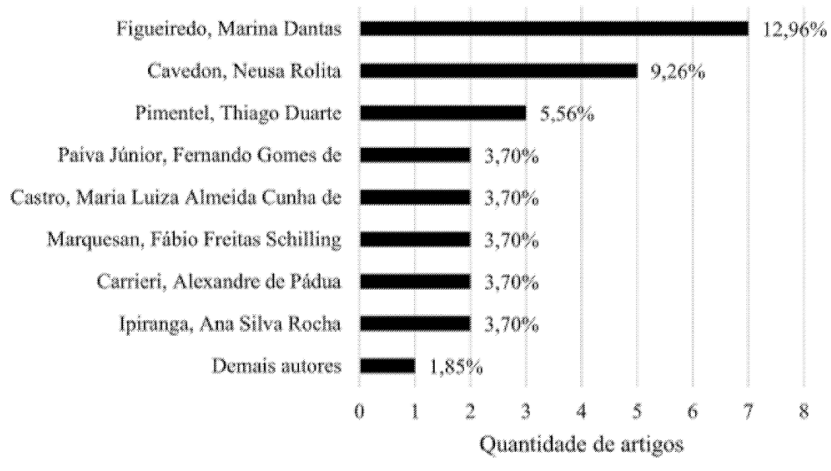

Fonte: Elaborado pelos autores.

Em termos de autores para cada instituição, calculouse uma média aritmética de 3,88 com um desvio padrão de 3,17, isto é, a distância dos valores em relação à média quase se igualou a essa última. Isso foi possível devido recorrência de apenas três instituições de pesquisa das quais 37 autores faziam parte, inclusive duas das três instituições foram as mesmas instituições das duas pesquisadoras mais recorrentes anteriormente citadas. As três instituições foram: UFMG (13 autores), UFRGS (12 autores) e UNIFOR (12 autores) (GRÁFICO 2). Isso mostra, entre outros pontos, que o artesanato tem despertado interesse de pesquisadores de instituições conhecidas no campo.

Gráfico 2 . Quantidade de pesquisadores por instituição de pesquisa

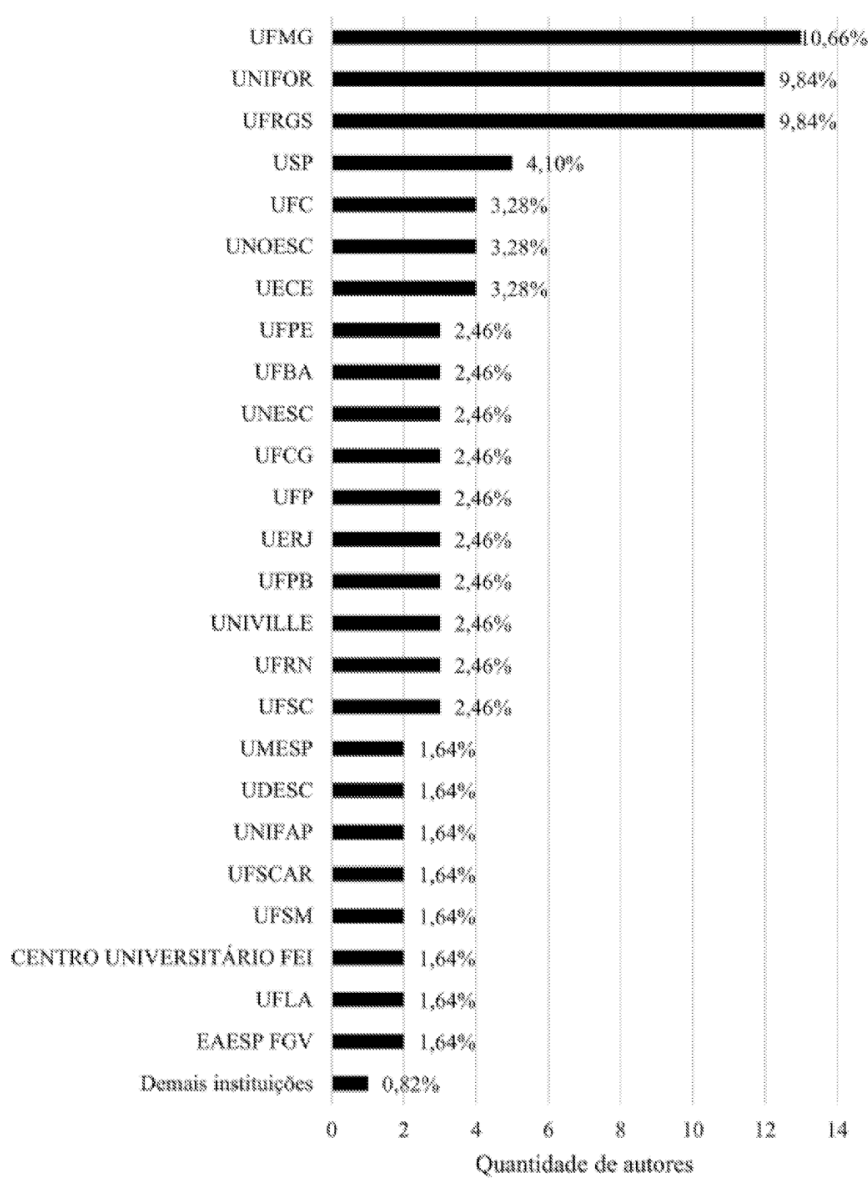

Fonte: Elaborado pelos autores.

O Gráfico 3 apresenta a frequência de publicação dos periódicos sobre a temática do artesanato nos estudos organizacionais. Dois periódicos se destacaram, Revista Interdisciplinar de Gestão Social (RIGS) e Organizações e Sociedade (O\&S), com as maiores quantidades de artigos, ficando o primeiro com 10 $(18,52 \%)$ e o segundo com 5 (9,26\%), em um total de 
54 artigos. Os demais periódicos não apresentaram mais do que 3 artigos. A recorrência desses dois periódicos da Escola de Administração da UFBA é compreensível. A RIGS dedicou um número inteiro (2012, n. 3) sobre artesanato, contando com 6 artigos, além de mais 4 artigos que faziam parte de outras edições da revista. Acerca da O\&S, é notório o seu escopo com o intuito de disseminar variados trabalhos, especialmente aqueles que se apresentam como alternativa ao mainstream, como é o caso da maioria dos trabalhos que articulam a temática do artesanato. Com a análise da amostra, constatou-se que, embora existam algumas pesquisas com enfoque funcionalista, grande parte dos estudos partiu de enfoques alternativos.

Gráfico 3 . Quantidade de artigos por periódico

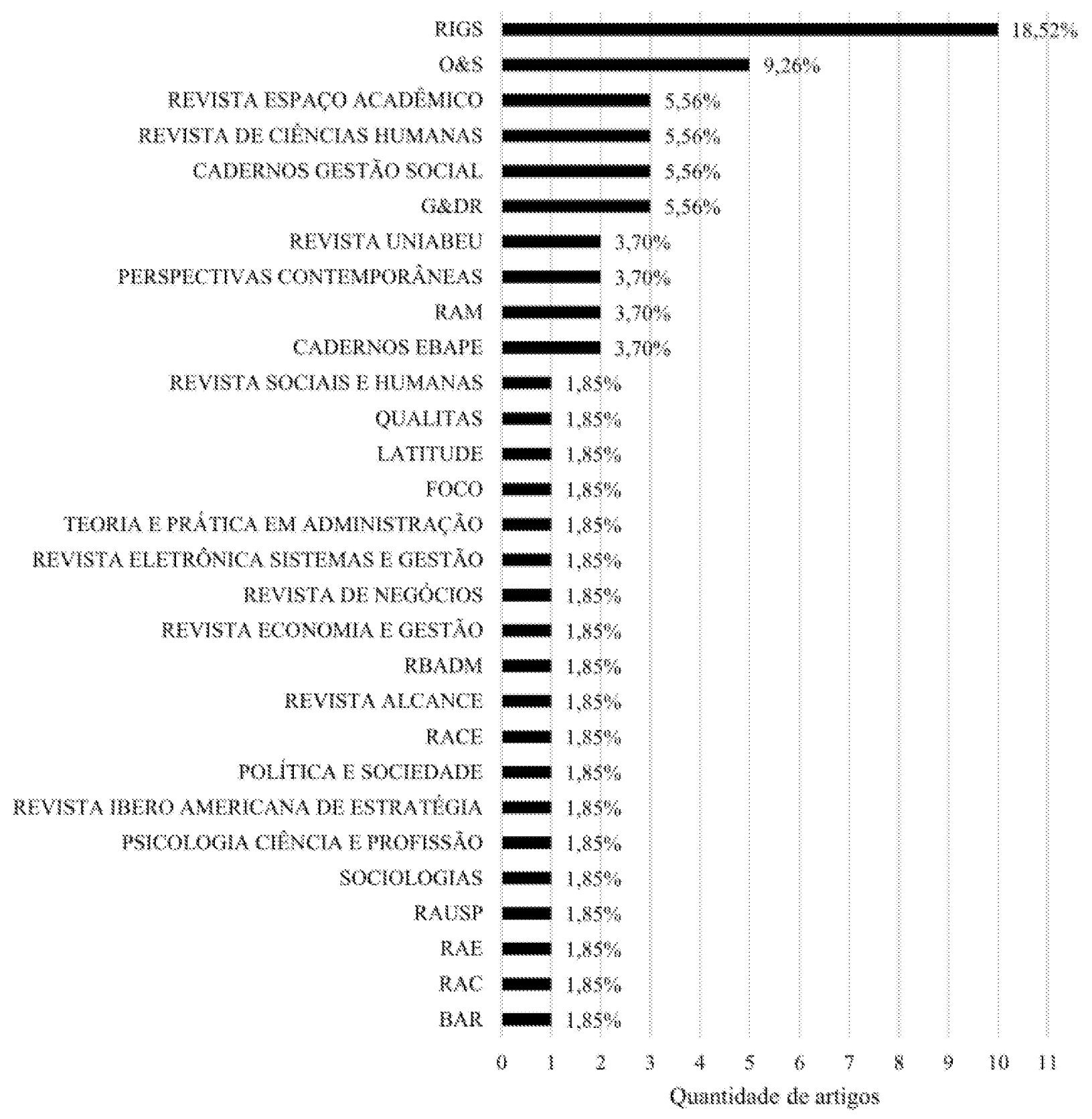

Fonte: Elaborado pelos autores.

O Gráfico 4 a seguir apresenta os temas mais recorrentes dessas pesquisas. Constatou-se que quatro temas foram mais recorrentes: pesca artesanal (8 artigos), relações entre artesanato e design (5 artigos), relações de trabalho (4 artigos) e economia solidária (4 artigos). Nota-se, assim, que esses são exemplos de temas que geralmente se 
apresentam na literatura dos estudos organizacionais como territórios propícios aos pesquisadores que escapam da maneira tradicional de se pensar gestão. Nesse contexto se encontra, por exemplo, um dos estudos com o tema da pesca artesanal - o estudo de Meneghetti e Faria (2012) - ao qual teve o objetivo de entender o processo de reificação de pescadores artesanais da cidade de Matinhos, usando como referencial o marxismo ocidental. Outros artigos basearam-se em enfoques mais voltados para a hermenêutica ou a fenomenologia. De qualquer maneira, ficou evidente nessa temática, a presença de pesquisas que se distanciaram do funcionalismo na administração, mesmo que se possa abordar essa e as outras temáticas de forma instrumental, como fizeram alguns autores da amostra.

Gráfico 4 . Quantidade de artigos por tema

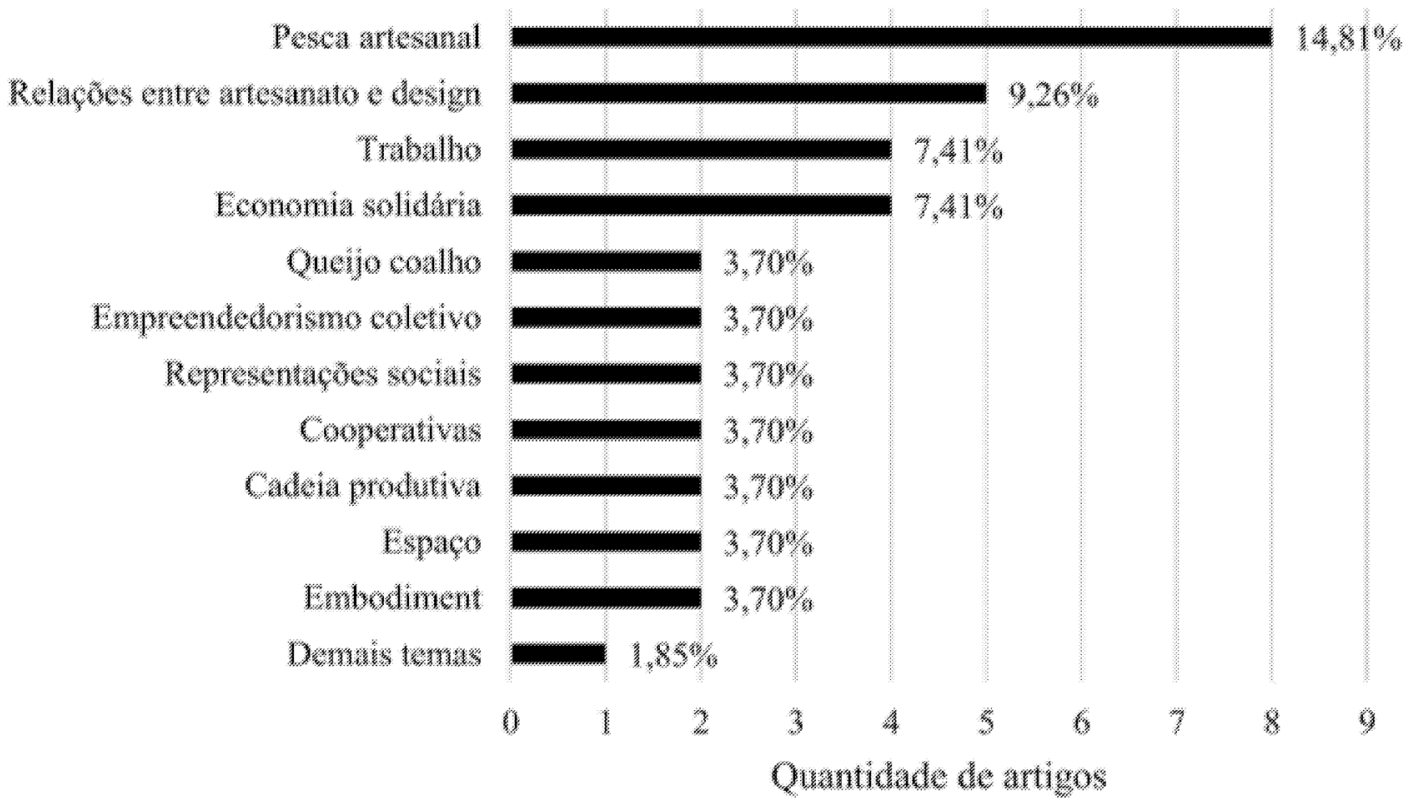

Fonte: Elaborado pelos autores.

A última característica tratada na dimensão dos aspectos gerais dos artigos se refere à distribuição dos artigos a cada ano, ao longo dos dez anos investigados, conforme pode ser visualizado no Gráfico 5. A partir do gráfico, fica evidente o destaque do ano de 2012 com 16 artigos (29, 63\%) do total de 54. A média de artigos por ano foi de 5,4 e o desvio padrão foi de 3,8. 
Gráfico 5. Quantidade de artigos por ano

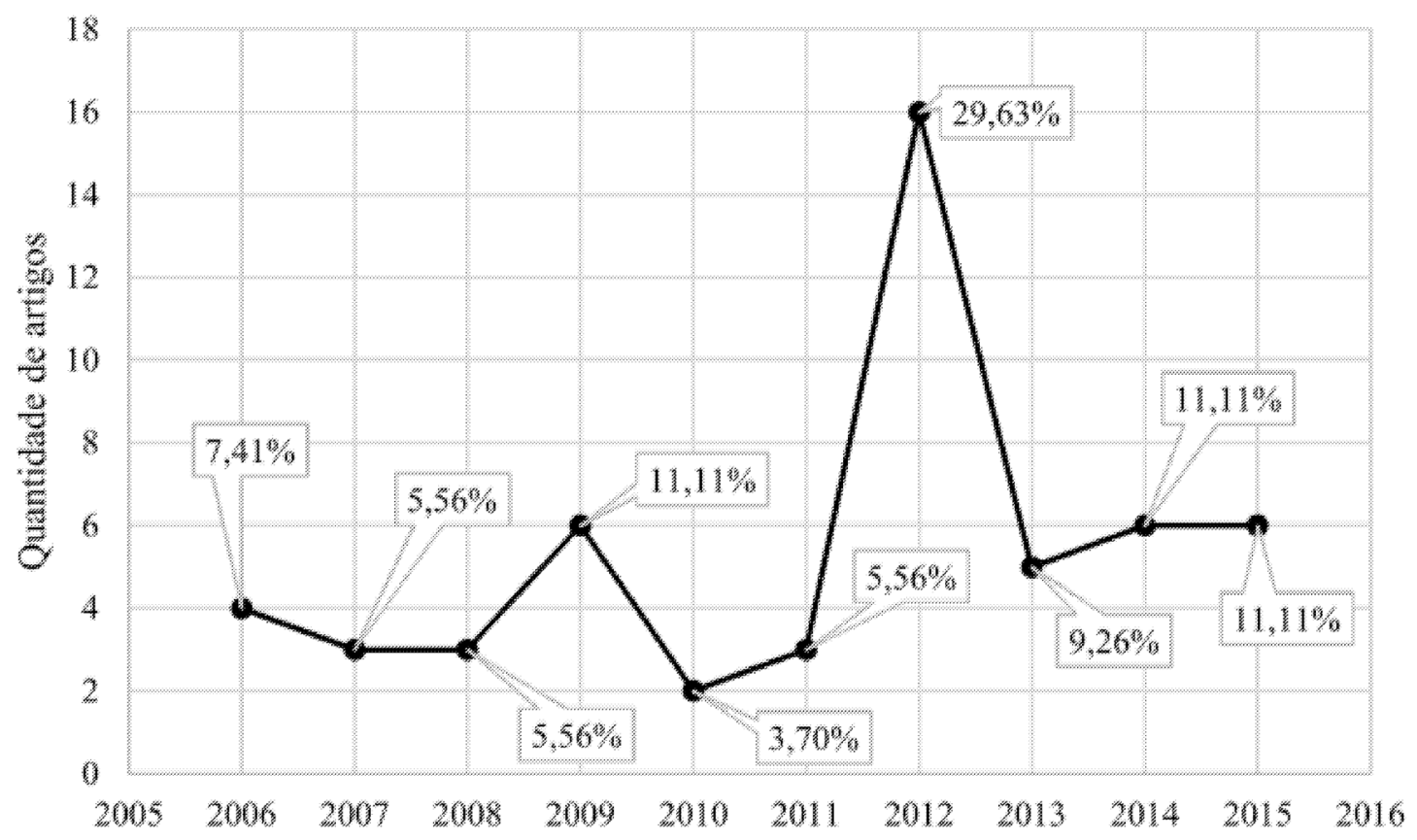

Fonte: Elaborado pelos autores.

Diante dessa primeira dimensão, que se voltou para as características gerais dos trabalhos selecionados na amostra, notou-se, em termos absolutos, o reduzido número de trabalhos e de pesquisadores que abordaram o artesanato. A despeito do pico de publicações que ocorreu em 2012, ele ocorreu devido a um número especial da revista RIGS sobre o tema, não se mantendo nos anos seguintes. Por outro lado, dentro desse cenário, a evidente diversidade de temas articulados com o artesanato (Gráfico 4) fica ainda mais destacada ao se considerar o reduzido número de artigos em dez anos no Brasil. Essa constatação reforça o potencial da temática do artesanato em oferecer frutos diversos ao campo dos estudos organizacionais.

A segunda dimensão investigada tratou de aspectos metodológicos dos artigos. Em termos dos tipos de artigo, constata-se no Gráfico 6 a predominância de artigos empíricos, correspondendo a 43 artigos do total de 54 . Dessa forma, notou-se a escassez de trabalhos teóricos sobre artesanato. Isso indica algumas oportunidades para os pesquisadores dos estudos organizacionais: buscar novas "lentes organizacionais" para olhar o artesanato ou buscar "lentes artesanais" para estudar as organizações, atentando-se para as oportunidades de desenvolvimentos epistemológicos para o campo. Trabalhos nessa via podem experimentar diversos caminhos para teorizar, seja buscando, por exemplo, aspectos historiográficos ou se embasando na teoria social para seus ensaios teóricos. Inclusive se pode problematizar a própria noção de artesanato, questionando-se sobre os limites do artesanato enquanto artesanato. 
Gráfico 6 . Quantidade de artigos por natureza da pesquisa

$\$ 0$

45

$79,63 \%$

40

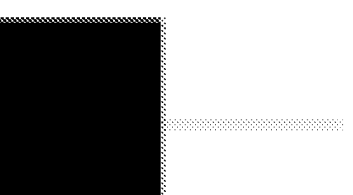

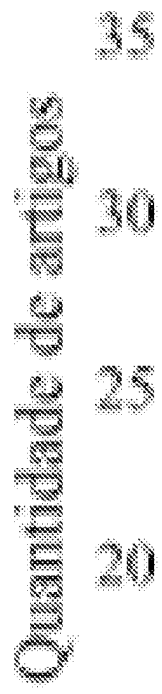

15

$20,37 \%$

10

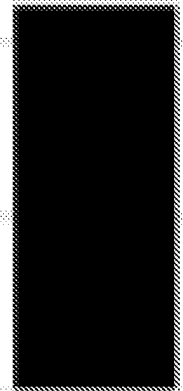

Teorico

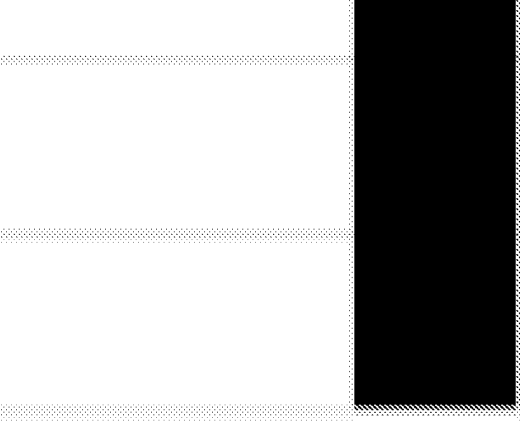

Empirico

Fonte: Elaborado pelos autores.

O fortalecimento da base teórica proporcionará ganhos para a temática e para os estudos organizacionais. As contribuições potenciais para esse último surgem ao se pensar o artesanato não apenas como um objeto 
de estudo, mas como uma abordagem para estudar outros temas dentro dos estudos organizacionais. Nesse caminho se encontram 4 artigos da amostra que fizeram do artesanato uma "lente" para investigar assuntos diversos, tais como criação de saberes por meio de práticas corporais, sociabilidades, espaço e estética nos estudos organizacionais. Isso pode ser confirmado no Gráfico 7 que apresenta as quantidades de artigos que trataram o artesanato como "objeto de estudo" e como "lente de análise".

Gráfico 7 . Quantidade de artigos por tratamento do artesanato

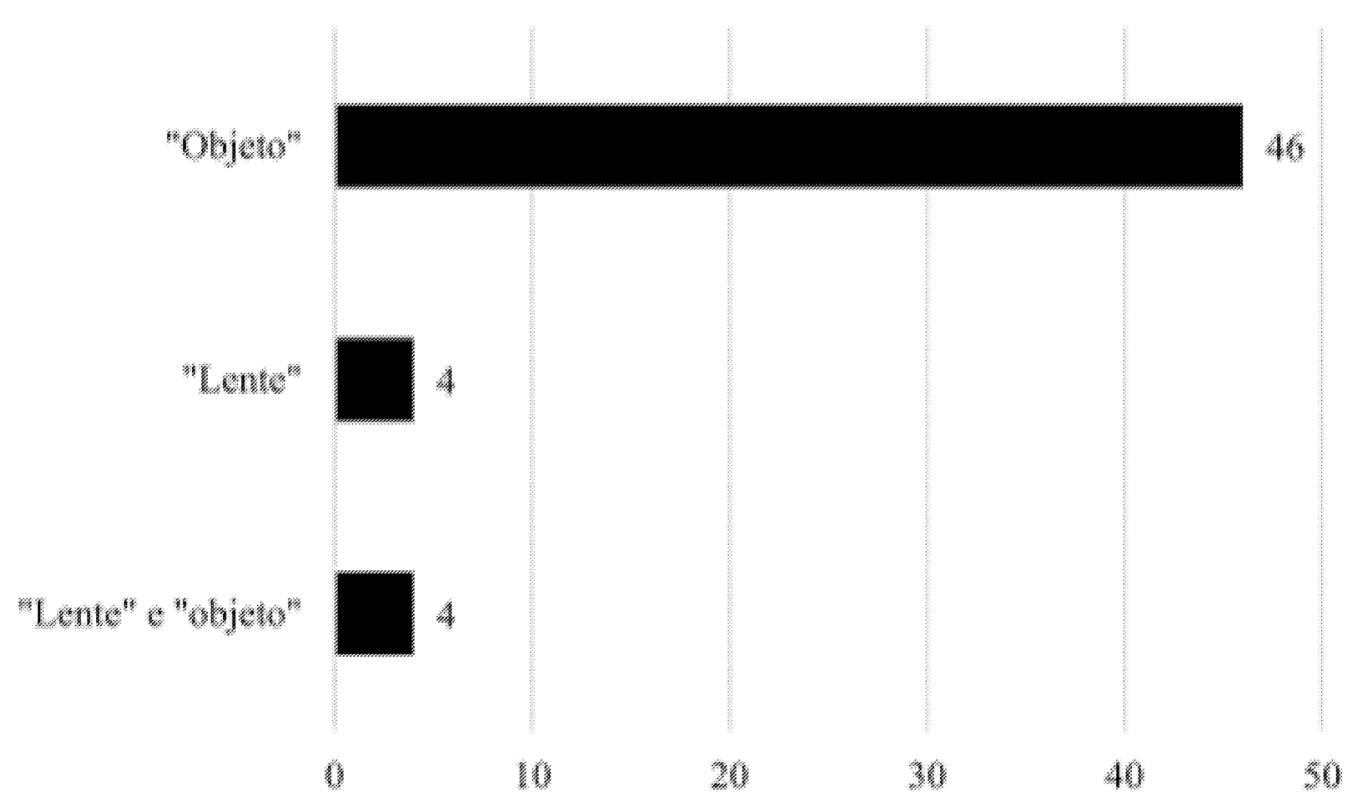

Fonte: Elaborado pelos autores.

Já em torno da classificação dos artigos empíricos, ampla maioria se caracterizou como pesquisa de cunho qualitativo (39 artigos) (GRÁFICO 8). Além disso, no que se refere à estratégia metodológica, o Gráfico 9 mostra que as estratégias recorrentes foram o estudo de caso e a etnografia, sendo que 13 artigos não explicitaram a estratégia. Com relação às técnicas de coleta de dados, observa-se a recorrência da entrevista, que apareceu em 37 dos 43 artigos empíricos (GRÁFICO 10). E sobre as técnicas de análise, verifica-se, pelo Gráfico 11, a recorrência da análise de conteúdo entre os artigos que explicitaram a técnica de análise empregada, porém, esses foram poucos, tendo em vista que 29 dos 43 artigos empíricos não esclareceram a técnica de análise no percurso metodológico. 
Gráfico 8 . Quantidade de artigos empíricos por tipo de pesquisa

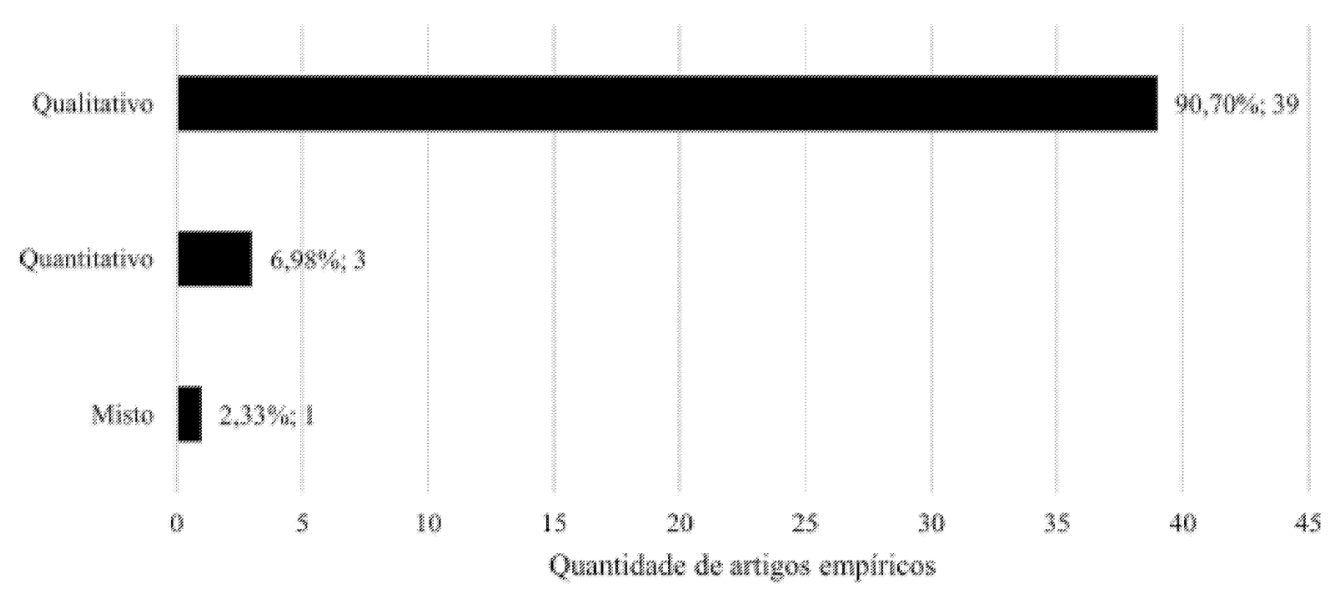

Fonte: Elaborado pelos autores.

Gráfico 9. Quantidade de artigos empíricos por estratégia metodológica

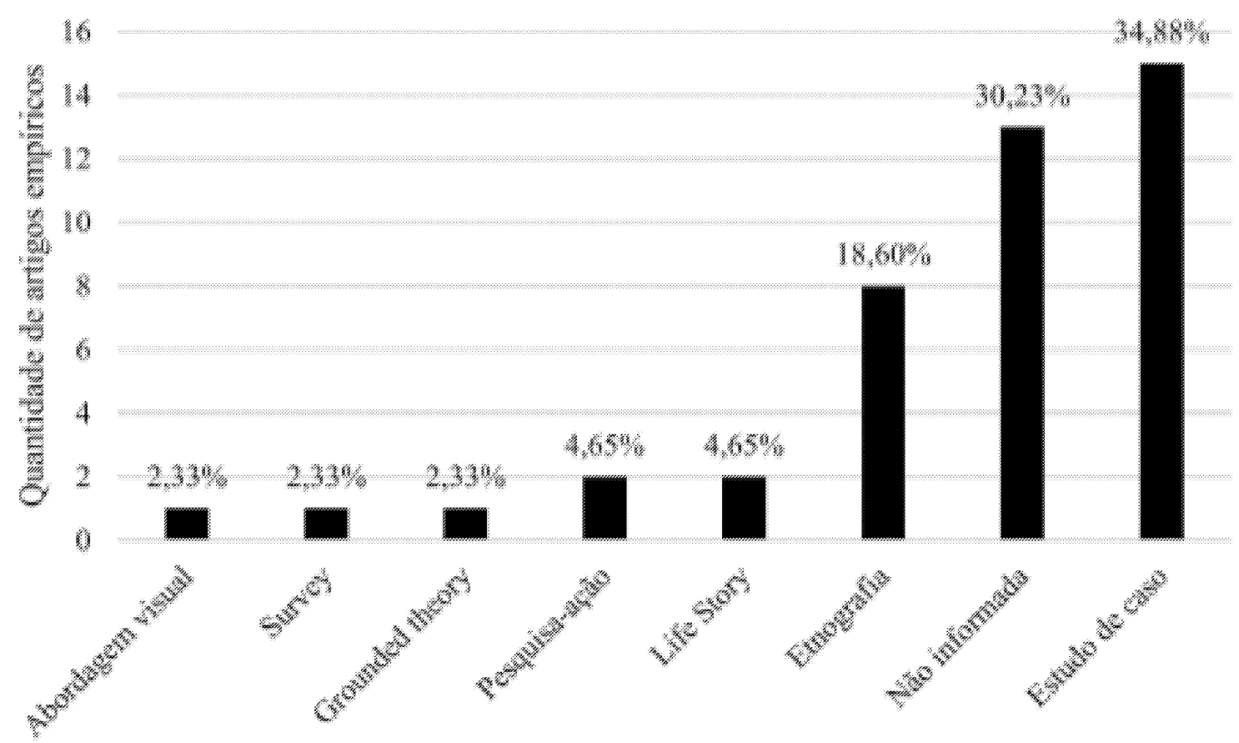

Fonte: Elaborado pelos autores. 
Gráfico 10 . Quantidade de artigos empíricos por técnica de coleta

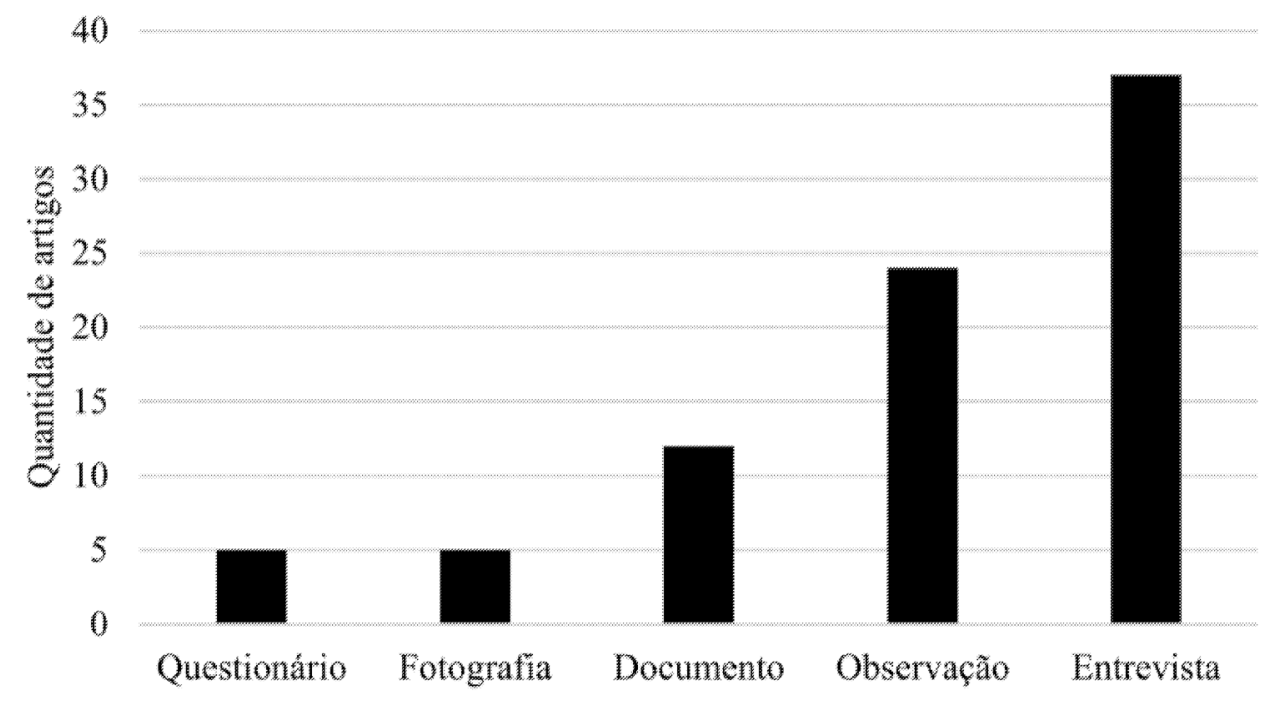

Fonte: Elaborado pelos autores.

Gráfico 11 . Quantidade de artigos empíricos por técnica de análise

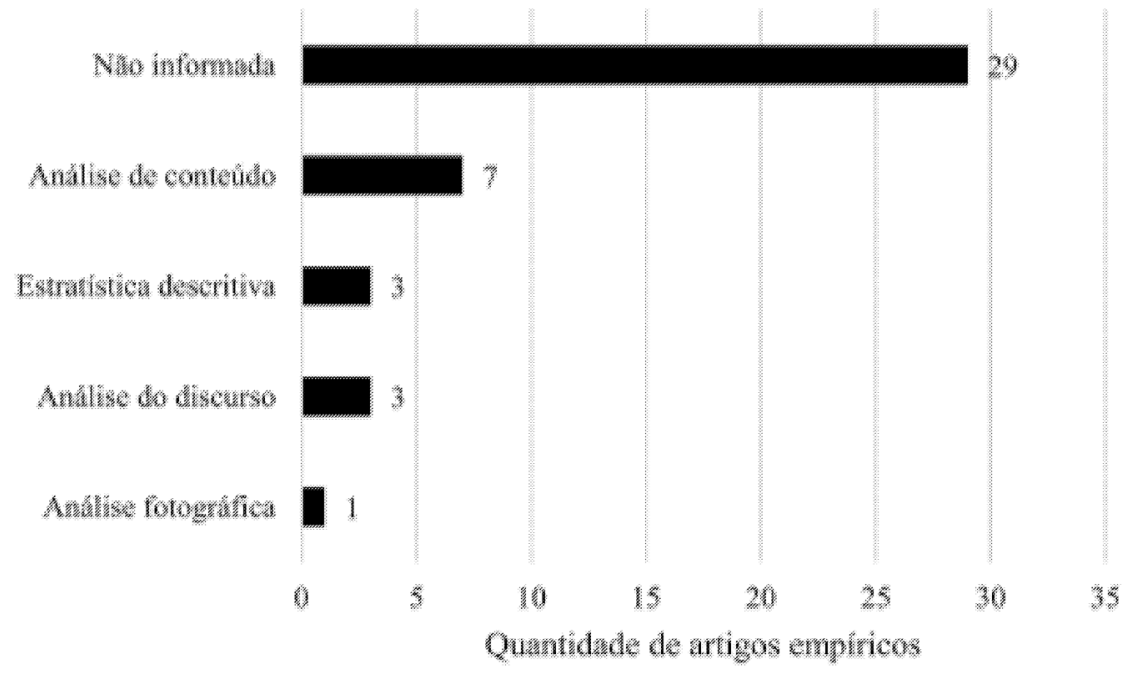

Fonte: Elaborado pelos autores. 
Em torno desses resultados dos artigos empíricos, duas considerações podem ser feitas. A primeira é que existe a chance de ampliação das estratégias metodológicas usadas pelos pesquisadores, quando se nota certa restrição com o destaque exclusivo no estudo de caso e na etnografia. Não se constatou, por exemplo, trabalho que partisse da pesquisa narrativa, da estratégia fenomenológica ou da historiografia. Além disso, pesquisadores podem explorar as várias etnografias, como a netnografia e a fotoetnografia. A segunda consideração é que, assim como a estratégia metodológica, as técnicas de coleta e análise não se mostraram diversificadas, surgindo oportunidades para estudos empíricos futuros. Esses estudos podem incluir técnicas como a construção de desenhos, os grupos focais, os mapas cognitivos, shadowing e a análise de narrativas, apenas para citar algumas dentre várias técnicas possíveis. A pluralidade de métodos e técnicas tem muito a enriquecer os achados das pesquisas acerca do artesanato. Porém, alerta-se para a adequada vigilância metodológica para que as técnicas sejam examinadas com o intuito de que elas possam se compatibilizar com as raízes epistemológicas adotadas nos estudos.

Como forma de exemplificação, nota-se o caso da shadowing, que se trata de uma técnica de pesquisa em que o pesquisador segue como uma sombra determinado membro do contexto organizacional ao longo de um período de tempo que pode durar desde um dia até uma semana ou mais (MCDONALD, 2005). Essa técnica se mostra significativamente compatível, entre outros contextos, com as pesquisas sobre a perspectiva das práticas. Bispo (2015) explana que a shadowing é relevante para os estudos baseados em prática pelo fato de que, por meio da técnica, os pesquisadores podem aprimorar o entendimento da dinâmica das práticas pesquisadas pelo acompanhamento das atividades ensaiadas pelos praticantes que estão sendo seguidos. Nesse sentido, pesquisadores que se entrelaçarem nos estudos baseados em prática com foco no artesanato podem fazer uso dessa técnica, pois não haverá incompatibilidade entre os pressupostos epistemológicos e a técnica.

\section{Algumas aplicações do artesanato nos estudos organizacionais}

Como forma de detalhar as maneiras pelas quais pesquisadores dos estudos organizacionais trataram o artesanato, apresenta-se a seguir três importantes estudos inseridos na amostra que explicitam algumas das características discutidas anteriormente.

Cavedon e Ferraz (2006) trataram o artesanato apenas como um locus de investigação. O objetivo da pesquisa dessas autoras foi revelar as culturas organizacionais de uma loja de economia popular solidária constituída por grupos autogestionários de artesãs da capital do Rio Grande do Sul, analisando como tais culturas influenciavam o sistema e o processo da autogestão. Como lente teórica, as autoras se basearam nas discussões sobre economia popular solidária, autogestão e cultura organizacional. A estratégia metodológica utilizada foi a etnografia. Como resultado da pesquisa, as autoras encontraram três blocos de discurso das artesãs. O primeiro bloco foi chamado de voluntárias, pois as artesãs aí incluídas tinham mais sintonia com a proposta mais profunda do projeto que se tratava da mudança social e consequente redução das desigualdades. O segundo bloco foi chamado de bloco da socialização, pois algumas artesãs alegaram que o motivo da inserção no projeto foi pela chance de construírem novas amizades. O terceiro bloco foi o bloco das beneficiadas, pois algumas artesãs tinham o interesse meramente financeiro de aumentarem suas próprias rendas e desconheciam as propostas da economia popular solidária. Portanto, a principal conclusão do estudo foi a de que o motivo do insucesso da iniciativa se deu pela tentativa do poder público de homogeneizar a cultura que se apresentou fragmentada.

Diferentemente desse estudo empírico, Figueiredo e Ipiranga (2015) trataram o artesanato como lente a fim de analisar os tipos de saber-fazer, por exemplo a mestria, que se realizam a partir da encarnação de praticantes, quando esses constroem suas identidades profissionais. A discussão construída pelas autoras se baseou na fenomenologia e na relevância do corpo para os estudos organizacionais. A lente do artesanato foi relevante para o estudo, já que as autoras concluíram que a aprendizagem se dá na prática, com a encarnação de habilidades e isso influencia nas identidades, em um entendimento de que o saber é inseparável do fazer.

No caso do estudo de Grande e outros (2012), o artesanato foi tratado ao mesmo tempo como lente e contexto de investigação. O objetivo do estudo foi "apresentar algumas análises das características do fazer artesanal de forma a mostrar como a presença do mestre artesão atravessa de forma central o 
processo, o produto e a comercialização" (GRANDE et al., 2012, p. 28). Duas atividades artesanais foram o contexto investigado: a de um mestre cervejeiro e a de um mestre da cachaça. A lente teórica utilizada teve como base três categorias: saber-fazer, aprendizagem e transmissão do saber artesanal. Um dos principais autores utilizados foi Sennet (2009). A pesquisa foi qualitativa com uso de documentos, observações e entrevistas para coleta. Os autores concluíram que, no contexto estudado, havia um hibridismo do artesanato, que colocava em confronto, por um lado, valores como tradição, fazer manual e visão holística, e por outro lado, a necessidade de adequação à lógica de mercado.

\section{Considerações finais}

O objetivo desta pesquisa foi compreender as maneiras pelas quais pesquisadores do campo dos estudos organizacionais brasileiros utilizaram o artesanato em suas investigações no período de 2006-2015. A partir da estratégia metodológica da bibliometria, o objetivo da pesquisa foi alcançado. Apresentou-se, neste estudo, os principais periódicos com artigos sobre o tema e os autores potenciais para serem seguidos pelas próximas pesquisas interessadas no alargamento da temática. Acima de tudo, discutiu-se sobre os caminhos percorridos e também sobre os caminhos não percorridos pelos pesquisadores da amostra. $\mathrm{O}$ destaque dos caminhos não percorridos foi relevante para se ter noção acerca das limitações e vazios da literatura, o que pode ser usado como referência em futuros trabalhos.

Diante disso, como contribuição deste artigo, propõese uma agenda de pesquisas constituída por três aspectos. O primeiro aspecto diz respeito à maneira pela qual o artesanato foi tratado na literatura. Viuse que há uma escassez de trabalhos que fazem do artesanato uma lente analítica com potencial de aplicação aos estudos organizacionais. Dessa forma, surge a oportunidade de trabalhos futuros com esse enfoque. O estudo de Figueiredo e Ipiranga (2015) apresentado na seção anterior é um exemplo relevador de como a lente artesanal proporciona robustas contribuições aos estudos organizacionais.

Ao se tratar de uma lente pouco explorada nos estudos organizacionais, é necessário discutir os caminhos para adotar essa lente dentro de um rigor epistemológico, o que é tratado no segundo aspecto da agenda de pesquisa aqui proposta. Notou-se que em alguns artigos analisados não há a preocupação com o rigor epistemológico. Observou-se escolhas de determinados paradigmas sociológicos, mas com aportes de autores de paradigmas diferentes daqueles escolhidos, resultando em confusões paradigmáticas. Essas confusões levam ao questionamento da consistência teórica das contribuições articuladas em torno da lente do artesanato nesses artigos. Portanto, futuros estudos precisam discutir as implicações dessas inconsistências e propor caminhos para uma maior robustez epistemológica de estudos que articulam o artesanato como lente.

O terceiro aspecto da agenda de pesquisa se refere aos procedimentos metodológicos. Verificou-se que grande parte dos artigos empíricos não explicitaram a estratégia metodológica utilizada, nem mesmo a técnica de análise dos dados. Além disso, grande parte dos artigos ficaram restritos à tríade entrevista, observação e pesquisa documental como técnicas de coleta dos dados. Diante disso, futuros estudos precisam se atentar para o rigor metodológico, principalmente acerca da estratégia metodológica e da técnica de análise, explicitando-as no corpo do artigo e interligando-as aos pressupostos epistemológicos escolhidos. Ademais, os pesquisadores têm a oportunidade de ampliar o escopo das técnicas de coleta, principalmente quando se trata de pesquisa qualitativa, que predominou na amostra. Os estudos qualitativos são propícios à reinvenção das técnicas por parte dos pesquisadores (CARRIERI; PERDIGÃO; AGUIAR, 2014) e essa reinvenção tem o potencial de fortalecer ainda mais as pesquisas de determinada temática, no caso o artesanato.

Cada um dos três aspectos dessa agenda de pesquisa se legitima nos achados a partir da pesquisa bibliométrica aqui desenvolvida. Em conjunto, eles constituem as contribuições finais deste artigo, no sentido de oferecer possibilidades para o desenvolvimento dos estudos com foco no artesanato, em torno do propósito de aproveitar o amplo potencial do tema como lente teórica nos estudos organizacionais ou como uma temática a ser investigada em vários contextos. 


\section{Referências}

ALVES, J. N. et al. A economia solidária no centro das discussões: um trabalho bibliométrico de estudos brasileiros. Cadernos EBAPE, Rio de Janeiro, v. 14, n. 2, p. 243-257, 2016.

ARAÚJO, C. A. Bibliometria: evolução histórica e questões atuais. Em Questão, Porto Alegre, v. 12, n. 1, p. 11-32, 2006.

BISPO, M. Methodological reflections on practicebased research in Organization Studies. BAR, Rio de Janeiro, v. 12, n. 3, p. 309-323, 2015.

BODART, C. DAS N. Arte em conchas: cultura, trabalho e sobrevivência no capitalismo contemporâneo. Revista Clóvis Moura de Humanidades, v. 2, n. 1, p. 56-64, 2016.

BOURDIEU, P. Homo academicus. California: Stanford University Press, 1988.

BOURDIEU, P. Regras da arte: gênese e estrutura do campo literário. 2. ed. São Paulo: Companhia das Letras, 2005.

CARRIERI, A. DE P.; PERDIGÃO, D. A.; AGUIAR, A. R. A gestão ordinária dos pequenos negócios: outro olhar sobre a gestão em estudos organizacionais. RAUSP, São Paulo, v. 49, n. 4, p. 698-713, 2014.

CAVEDON, N. R.; FERRAZ, D. L. S. "Tricotando as redes de solidariedade": as culturas organizacionais de uma loja autogestionada de Economia Popular Solidária de Porto Alegre. O\&S, Salvador, v. 13, n. 39, p. 93-111, 2006.

CERTEAU, M. DE. A invenção do cotidiano 1: artes de fazer. 3. ed. Petrópolis: Vozes, 1998.

CERTEAU, M. DE; GIARD, L.; MAYOL, P. A invenção do cotidiano 2: morar, cozinhar. 9. ed. Petrópolis, RJ: Vozes, 2009.

COSTA, V. F.; ANDRADE, T. DE. Comportamento de cidadania organizacional: caracterização da produção científica internacional no período de 2002 a 2012. RAM, São Paulo, v. 16, n. 2, p. 45-71, 2015.

FIGUEIREDO, M. D. DE. O artesanato enquanto prática e materialidade: argumento para pensar a dimensão estética e os artefatos nos estudos organizacionais. RIGS, Salvador, v. 3, n. 1, p. 189205, 2014.
FIGUEIREDO, M. D. DE; IPIRANGA, A. S. R.

How can we define mastery? Reflections on learning, embodiment and professional identity. BAR, Rio de Janeiro, v. 12, n. 4, p. 348-364, 2015.

FIGUEIREDO, M. D. DE; MARQUESAN, F. F. S. Artesanato, arte, design... Por que isso importa aos estudos organizacionais? RIGS, Salvador, v. 3, n. 3, p. 127-143, 2014.

GRANDE, M. M. et al. Da tradição à modernidade: o savoir-faire do mestre de ofício na produção da cerveja e da cachaça artesanais. RIGS, Salvador, v. 1, n. 3, p. 25-48, 2012.

IBGE. Pesquisa de informações básicas municipais - 2009. Rio de Janeiro, 2010.

MARQUESAN, F. F. S.; FIGUEIREDO, M. D. DE. De artesão a empreendedor: a ressignificação do trabalho artesanal como estratégia para a reprodução de relações desiguais de poder. RAM, São Paulo, v. 15, n. 6, p. 76-97, 2014.

MAZZA, A. C. A.; IPIRANGA, A. S. R.; FREITAS, A. A. F. DE. O design, a arte e o artesanato deslocando o centro. Cadernos EBAPE, Rio de Janeiro, v. 5, n. 4, p. 1-11, 2007.

MCDONALD, S. Studying actions in context: a qualitative shadowing method for organizational research. Qualitative research, London, v. 5, n. 4, p. 455-473, 2005.

MENEGHETTI, F. K.; FARIA, J. H. DE. Gestão e reificação dos homens do mar. RAM, São Paulo, v. 13, n. 4, p. 15-47, 2012.

OLIVEIRA, J. S. DE; CAVEDON, N. R.;

FIGUEIREDO, M. D. O artesanato na ótica de quem o produz: com a palavra os artesãos do brique da redenção em Porto Alegre. RIGS, Salvador, v. 1, n. 3, p. 141-162, 2012.

PROUS, A. Arqueologia brasileira. Brasília, DF: Editora Universidade de Brasília, 1992.

SENNET, R. O artífice. 2. ed. Rio de Janeiro: Record, 2009.

VERGARA, S.; SILVA, H. Organizações artesanais: um sistema esquecido na teoria das organizações.

Revista Portuguesa e Brasileira de Gestão, v. 6, n. 3, p. 32-38, 2007.

WACQUANT, L. Mapear o campo artístico. Sociologia, Problemas e Práticas, n. 48, p. 117123, 2005. 